\title{
PENGARUH STRES KERJA, KOMITMEN ORGANISASI, DAN KEPUASAN KERJA KARYAWAN TERHADAP TURNOVER INTENTION
}

\author{
Ni Nyoman Yani Sri Lestari ${ }^{1}$ \\ Ni Wayan Mujiati² \\ ${ }^{1,2}$ Fakultas Ekonomi dan Bisnis Universitas Udayana, Bali, Indonesia \\ e-mail: lestari.feb@gmail.com
}

\begin{abstract}
ABSTRAK
Tingginya tingkat turnover intention pada kayawan akan menimbulkan dampak negatif bagi perusahaan yang dapat menciptakan ketidakstabilan dan menunjukkan bahwa perusahaan tersebut tidak efektif, oleh sebab itu suatu perusahaan harus mengetahui faktorfaktor yang dapat menyebabkan turnover intention. Tujuan penelitian ini adalah untuk menguji pengaruh stres kerja, komitmen organisasi dan kepuasan kerja terhadap turnover intention. Penelitian ini dilakukan pada pada PT. Bank Rakyat Indonesia (Persero) Tbk. Cabang Gatot Subroto Denpasar. Jumlah responden penelitian yang diambil sebanyak 70 karyawan. Teknik analisis yang digunakan adalah regresi linier berganda. Hasil penelitian menunjukkan bahwa stres kerja berpengaruh positif dan signifikan terhadap turnover intention. Komitmen organisasi berpengaruh negatif dan signifikan terhadap turnover intention. Kepuasan kerja berpengaruh negatif dan signifikan terhadap turnover intention.
\end{abstract}

Kata Kunci: turnover intention, stres kerja, komitmen organisasi, kepuasan kerja.

\begin{abstract}
The high level of turnover intention on the rich will cause a negative impact for companies that can create instability and show that the company is not effective, therefore a company must know the factors that can cause turnover intention. The purpose of this study was to examine the effect of work stress, organizational commitment and job satisfaction on turnover intention. This research was conducted at PT. Bank Rakyat Indonesia (Persero) Tbk. Gatot Subroto Branch Denpasar. The number of research respondents taken as many as 70 employees. The analysis technique used is multiple linear regression. The results showed that work stress had a positive and significant effect on turnover intention. Organizational commitment has a negative and significant effect on turnover intention. Job satisfaction has a negative and significant effect on turnover intention.
\end{abstract}

Keywords: turnover intention, work stress, organizational commitment, job satisfaction. 


\section{PENDAHULUAN}

Keinginan untuk berpindah (turnover intention) merupakan permasalahan yang sangat serius dalam manajemen sumber daya manusia (Fah et al., 2010). Permasalahan dalam SDM akan menentukan keberhasilan dalam mencapai tujuan suatu perusahaan, dimana tujuan tersebut tidak akan tercapai apabila karyawan tidak melaksanakan pekerjaan dengan baik (Sylvia, dkk., 2014). Untuk mewujudkan hal tersebut diperlukannya sumber daya manusia yang berkualitas agar dapat mencapai tujuan yang diinginkan perusahaan.

Sumber daya manusia berkualitas tentu akan memberikan dampak positif setiap perusahaan, salah satunya di dunia perbankan. Faktor utama dalam keberhasilan organisasi itu sendiri yaitu Sumber Daya Manusia, karena Sumber Daya Manusia (SDM) tersebut yang akan mengelola seluruh sumber daya manusia yang dimiliki oleh perusahaan. Pentingnya memiliki kualitas sumber daya manusia dalam perusahaan perbankan yaitu pertama semakin tinggi tingkat kebutuhan masyarakat dalam dunia perbankan, masyarakat akan memilih salah satu bank dengan pelayanan terbaik yaitu melayani dengan setulus hati dan terpercaya. Kedua, semakin tingginya persaingan antar perbankan. Apabila perusahaan memberikan pelayanan terbaik kepada nasabah, akan mendapatkan point tersendiri pada perusahaan yaitu kepercayaan nasabah, citra yang baik pada perusahaan, meningkatkan eksistensi perusahaan serta memperoleh laba yang diharapkan dapat tercapai.

Bank Rakyat Indonesia (BRI) adalah salah satu bank milik pemerintah yang terbesar di Indonesia. Pada awalnya Bank Rakyat Indonesia (BRI) didirikan di 
Purwokerto, Jawa Tengah oleh Raden Bei Aria Wirjaatmadja dengan nama De Poerwokertosche Hulp en Spaarbank der Inlandsche Hoofden atau "Bank Bantuan dan Simpanan Milik kaum Priyai Purwokerto". Lembaga tersebut berdiri tanggal 16 Desember 1895, yang kemudian dijadikan hari kelahiran BRI. Kantor Pusat Bank Rakyat Indonesia (BRI) berlokasi di Gedung BRI I, Jalan Jendral Sudirman Kav. 44-46, Jakarta 10210. Saat ini, Bank BRI memiliki 19 kantor wilayah, 1 kantor inspeksi pusat, 19 kantor inspeksi wilayah, 462 kantor cabang domestik, 1 kantor cabang khusus, 609 kantor cabang pembantu, 984 kantor kas, 5.380 BRI unit, 3.180 teras \& teras keliling dan 3 teras kapal. Dasar dari kegiatan perbankan adalah kepercayaan, tanpa adanya kepercayaan dari masyarakat terhadap perbankan dan juga sebaliknya pihak perusahaan terhadap masyarakat kegiatan perbankan tidak dapat berjalan dengan baik (Darsana, 2009:37). Penelitian ini dilakukan pada PT. Bank Rakyat Indonesia (persero) Tbk. Cabang Gatot Subroto Denpasar yang berlokasi di Jalan Gatot Subroto No. 362, Denpasar, Bali.

Turnover intention merupakan salah satu bentuk perilaku menarik diri (withdrawal) dalam dunia kerja, akan tetapi sekaligus juga merupakan hak bagi setiap individu untuk menentukan pilihannya apakah tetap bekerja atau keluar dari perusahaan tersebut. Namun perilaku seperti itu tidaklah buruk sebab bisa saja seorang karyawan ingin keluar dari tempat dimana ia bekerja untuk mendapatkan kesempatan yang jauh lebih baik untuk bekerja di tempat lain atau juga ingin keluar karena sudah tidak tahan dengan situasi di tempatnya bekerja saat itu (Yulianto, dalam Sidharta \& Margetha (2011). Turnover Intention perlu 
mendapatkan perhatian yang serius dari pihak manajemen perusahaan terutama devisi sumber daya manusia, karena akan berakibat negatif jika tidak ditangani. Tingginya tingkat turnover intention pada kayawan akan menimbulkan dampak negatif bagi perusahaan yang dapat menciptakan ketidak stabilan dan ketidak pastian terhadap kondisi tenaga kerja serta dalam peningkatan sumber daya manusia.

Turnover intention yang tinggi dapat menunjukkan bahwa perusahaan tersebut tidak efektif, mengurangi efisiensi serta produktivitas sehingga dapat membahayakan perusahaan, pada akhirnya perusahaan kehilangan karyawan yang sudah memiliki pengalaman sebelumnya dan perlu melatih karyawan yang baru (Joarder et al., 2011). Keputusan karyawan meninggalkan perusahaan inilah yang menjadi masalah besar bagi setiap perusahaan (Mahdi et al.,2012). Penelitian ini sangat penting untuk mengetahui penyebab tingginya turnover intention di suatu perusahaan, untuk mengurangi biaya, serta kerugian perusahaan. Ada banyak factor yang mempengaruhi turnover intention diantaranya adalah stres kerja, komitmen organisasi, kepuasan kerja dan sebagainya (Sutanto dan Gunawan, 2013).

Agung dkk. (2013) telah melakukan penelitian dan berhasil membuktikan bahwa kepuasan kerja berpengaruh negatif dan signifikan terhadap turnover intention karyawan. Sementara itu, stres kerja berpengaruh positif dan signifikan terhadap turnover intention karyawan. Penelitian yang dilakukan oleh Manurung (2012) menunjukkan bahwa variabel stres kerja berpengaruh positif terhadap turnover intention karyawan. Kepuasan kerja berpengaruh negatif terhadap 
turnover intention karyawan. Suciati, dkk. (2015) menyatakan bahwa stress berpengaruh positif terhadap turnover intention. Ahmad et al. (2012) hasil dalam penelitiannya bahwa karyawan yang mengalami stres kerja tinggi memiliki niat yang tinggi untuk berhenti dari pekerjaannya. Siddiqui dan Jamil (2015) menyatakan bahwa stress berpengaruh langsung terhadap turnover intention. Hal ini berarti semakin tinggi tingkat stres kerja di perusahaan maka akan memicu tingginya tingkat turnover.

Salah satu penyebab keinginan karyawan keluar dari perusahaan disebabkan oleh stres kerja. Stres kerja merupakan sesuatu yang menyangkut interaksi antar individu dan lingkungan yaitu interaksi antara stimulasi dan respons. Jadi stres adalah konsekuensi setiap tindakan dan situasi lingkungan yang menimbulkan tuntunan psikologis dan fisik yang berlebihan pada seseorang (Sunyoto, 2015:54). Velnampy dan Aravinthan (2013) menyatakan bahwa stres kerja adalah pola emosional perilaku kognitif dan reaksi psikologis terhadap aspek yang merugikan dan berbahaya dari setiap pekerjaan, organisasi kerja dan lingkungan kerja. Stres kerja terjadi ketika ada ketidakseimbangan antara tuntutan tempat kerja dan kemampuan pekerja untuk mengatasi masalah (Mosadeghrad, 2013). Stres kerja adalah kondisi dinamik yang didalamnya individu menghadapi peluang, kendala (constraints), atau tuntutan (demands) yang terkait dengan apa yang sangat diinginkannya dan yang hasilnya dipersepsikan sebagai tidak pasti tetapi penting (Robbins, 2006). Faktor-faktor yang mempengaruhi stres kerja menurut Robbins (2006), yaitu faktor organisasi, faktor lingkungan, dan faktor individu. Dengan tuntutan tempat kerja dan kemampuan kerja yang mengharuskan karyawannya 
bekerja dengan sangat baik, itu mengakibatkan stres pada karyawan maka dari itu sebelum karyawan memulai bekerja pada sebuah perusahaan, harus mengetahui komitmen perusahaan tersebut.

Menurut Tobing (2009) komitmen karyawan merupakan tingkat keterikatan yang dimiliki karyawan terhadap perusahaannya dan dapat dijadikan jaminan untuk menjaga kelangsungan perusahaan tempat karyawan itu bekerja. Komitmen organisasional menunjukkan upaya seorang karyawan dalam melaksanakan pekerjaannya, setia kepada instansinya untuk pencapaian tujuan dan pengidentifikasian karyawan dalam memenuhi tujuan organisasi (Haq et al., 2014). Agar komitmen organisasi yang dimiliki karyawan tinggi, perusahaan harus berusaha memenuhi hak-hak karyawan agar mereka memiliki loyalitas dan komitmen yang tinggi Anis (2003). Perusahaan yang mampu memenuhi hakhak karyawan dapat mampu menciptakan loyalitas dan kepuasan kerja karyawan.

Kepuasan kerja adalah sikap emosional yang menyenangkan dan mencintai pekerjaannya. Sikap ini dicerminkan oleh moral kerja, kedisiplinan, dan prestasi kerja. kepuasan ini dinikmati dalam pekerjaan, luar pekerjaan dan kombinasi dalam dan luar pekerjaan. Karyawan dengan tingkat kepuasan rendah akan menunjukkan sikap negatif, baik terhadap pekerjaannya maupun terhadap terhadap lingkungan kerjanya, sehingga karyawan merasa tidak aman dalam dirinya dan merasakan kegelisahannya, hingga pada akhirnya karyawan akan niat berpindah dan meninggalkan pekerjaannya (Hanafiah, 2014). Lu et al. (2013) membagi kepuasan kerja ke dalam kepuasan kerja internal yaitu perasaan yang berasal dari hubungan individu dengan pekerjaan itu sendiri, dimana tingkat 
kepuasan tersebut diperoleh dari pekerjaan itu sendiri dan kepuasan kerja eksternal yaitu rasa kepuasan yang tidak berhubungan langsung antara alasan merasa puas dengan pekerjaan itu sendiri. Kepuasan kerja berorientasi pada sikap individu karyawan terhadap tugasnya, karyawan dengan tingkat kepuasan kerja yang tinggi memiliki sikap positif terhadap kewajibannya, sedangkan yang tidak puas akan memiliki sikap negatif terhadap kewajibannya, karyawan mempunyai tingkat kepuasan yang berbeda terhadap sistem nilai yang berlaku tingginya penilaian terhadap kegiatan dan keinginan yang dirasakan karyawan, berdampak pada tingginya kepuasan yang diperoleh maka kepuasan kerja adalah penilaian yang menunjukkan perasaan sikap kepuasan dalam bekerja (Septiadi dan Supartha, 2013).

Observasi dan wawancara yang dilakukan peneliti kepada Bapak Riza Kerta Yuda dan Ibu I Gusti Ayu Agung Rani, selaku Personalia SDM pada PT. Bank Rakyat Indonesia (Persero) Tbk. Cabang Gatot Subroto Denpasar, mengatakan bahwa dalam turnover karyawan pada perusahaan BRI salah satu di dunia perbankan, pada tahun 2014-2015 ada beberapa karyawan yang meninggalkan perusahaan diantaranya adalah bagian manajer pemasaran, yaitu AO (Account Officer), karyawan yang menawarkan kredit, memasarkan produk-produk perusahaan kepada calon nasabah, AAO (Associate Account Officer) asisten dari karyawan AO yang ikut menawarkan kredit kepada calon nasabah dan FO (Funding Officer) karyawan pencari dana kepada calon nasabah, sedangkan manajer operasional bagian pelayanan kasir nasabah (Teller) dan pelayanan nasabah (Customer Service), dikarenakan keinginan karyawan itu sendiri, dan dari 
pihak perusahaan bank tidak memperpanjang kontrak dari beberapa karyawan.

Turnover intention karyawan pada suatu organisasi mengakibatkan ketidakstabilan dan ketidakpastian terhadap kondisi tenaga kerja dan peningkatan biaya-biaya sumber daya manusia, seperti mengeluarkan biaya cukup besar pada perekrutan karyawan dan biaya pelatihan karyawan baru maupun karyawan yang sudah senior untuk memberikan pendidikan dan bekal pengetahuan tentang perusahaan, karyawan akan di training pada lembaga pelatihan khusus BRI "BRI CORPORATE UNIVERSITY" di Surabaya. Pendidikan yang diberikan setiap tingkatan jabatan mengharuskan karyawan untuk training artinya perusahaan sudah mengeluarkan biaya yang sangat besar dan menaruh harapan perusahaan kepada karyawannya. Turnover yang tinggi juga mengakibatkan perusahaan tidak efektif karena dapat kehilangan karyawan yang berpengalaman dan menghambat proses produksi dari suatu perusahaan.

Terjadinya turnover merupakan hal yang tidak dihendaki oleh perusahaan dimana salah satu penyebab turnover pada perusahaan yaitu stres karyawan, stres pada karyawan akan muncul bila terdapat ketidakseimbangan antara kemampuan individu dengan tuntutan dari pekerjaan salah satu penyebab stres pada karyawan antara lain : 1) tuntutan tugas yaitu adanya persaingan besar antar perbankan untuk karyawan dengan target tinggi sehingga beberapa karyawan stres tidak tercapainya target simpanan dan pinjaman dalam suatu perusahaan membuat semangat karyawan menurun, 2) tuntutan hubungan antar pribadi yaitu kemaampuan untuk mempertahankan yang saling menguntungkan ditandai dengan adanya sikap memberi dan menerima orang lain dalam situasi 
yang harmonis atau dalam kedekatan emosional antar karyawan, serta 3) tuntutan peran dalam melaksanakan kewajiban dan tanggung jawab karyawan pada perusahaan. Dapat dikatakan bahwa stres kerja dapat timbul jika tuntutan kerja tidak seimbangan dengan kemampuan untuk memenuhi tuntutannya tersebut sehingga menimbulkan berbagai taraf, antara lain : 1) taraf sedang, stres berperan sebagai motivator yang memberikan dampak positif pada tingkah laku termaksud tingkah laku kerja. 2) taraf tinggi, terjadi berulang-ulang dan berlansung lama sehingga individu merasakan ancaman, mengalami gangguan fisik, psikis, dan perilaku kerja (Suwatno dan priansa, 2013:255).

Dari uraian di atas, maka peneliti ingin menguji pengaruh stres kerja, komitmen organisasi dan kepuasan kerja karyawan terhadap turnover intention pada PT. Bank Rakyat Indonesia (Persero) Tbk. Cabang Gatot Subroto Denpasar. Tujuan akhir dari penelitian ini adalah memberikan solusi dan saran yang dapat diambil perusahaan guna menekan tingkat turnover intention karyawan dilihat dari sudut pandang stres kerja, komitmen organisasi dan kepuasan kerja karyawan.

Stres kerja karyawan menyebabkan kehilangan kemampuan untuk mengambil keputusan dan perilakunya menjadi tidak teratur dan memicu keinginan untuk keluar (Anggraini, 2013). Hal tersebut sesuai dengan hasil penelitian yang dilakukan oleh Waspodo dkk. (2013) dalam penelitiannya yang berjudul pengaruh kepuasan kerja, stres kerja terhadap turnover intention pada karyawan PT. Unitex di Bogor, menemukan bahwa stres kerja memiliki pengaruh positif terhadap turnover intention, ini artinya jika stres kerja meningkat maka 
turnover intention juga akan meningkat. Arnanta dkk. (2017) menambahkan bahwa stres berpengaruh positif terhadap turnover intention yang ditunjukkan dari nilai $\beta 0,323$ dan sig. 0,000 .

Stres merupakan penyebab utama terhadap turnover intention pada karyawan (Mitchell et al., 2014). (Arshadi et al., 2013) menunjukkan hasil penelitiannya bahwa stres kerja berpengaruh positif terhadap turnover intention ditunjukkan dari nilai r 0,45 p<0,01. Lee et al. (2016) menunjukkan hasil penelitian bahwa stres berpengaruh positif terhadap turnover intention. Young dan Kwon menyatakan dalam penelitiannya stres kerja berpengaruh positif terhadap turnover intention. Hal ini berarti semakin tinggi tingkat stres kerja yang dirasakan karyawan, maka semakin tinggi pula turnover intention karyawan yang terjadi pada PT. Bank Rakyat Indonesia (Persero) Tbk. Cabang Gatot Subroto Denpasar. Rumusan hipotesis dapat dinyatakan sebagai berikut.

$\mathrm{H}_{1}$ : Stres Kerja berpengaruh positif terhadap Turnover Intention pada PT. Bank Rakyat Indonesia (Persero) Tbk. Cabang Gatot Subroto Denpasar.

Menurut Jehanzeb, dkk. (2013) menunjukkan hasil penelitiannya bahwa komitmen organisasi berpengaruh negatif dengan keinginan keluar dari organisasi. Jonathan, et al. (2013) mendapatkan hasil bahwa komitmen organisasi berpengaruh negative terhadap terhadap keinginan keluar. Hal tersebut menunjukkan konsistensi komitmen organisasi dalam memprediksi keinginan karyawan untuk keluar dari organisasi. Monica (2017) dalam penelitiannya menemukan bahwa komitmen organisasional berpengaruh negatif terhadap turnover intention. Sianipar dan Haryanti (2014), menemukan hubungan yang negatif antara komitmen organisasional dan turnover intention. Kalidass dan 
Arsiah (2015) mendapatkan hasil bahwa komitmen organisasi dengan hubungan negatif terhadap turnover intention.

Hal ini berarti semakin tinggi tingkat komitmen organisasi yang dirasakan karyawan, maka semakin rendah tingkat turnover intention karyawan yang terjadi pada PT. Bank Rakyat Indonesia (Persero Tbk. Cabang Gatot Subroto Denpasar. Rumusan hipotesis dapat dinyatakan sebagai berikut.

$\mathrm{H}_{2}$ : Komitmen Organisasi berpengaruh negatif terhadap Turnover Intention pada PT. Bank Rakyat Indonesia (Persero) Tbk. Cabang Gatot Subroto Denpasar.

Ibrahim et.al (2016) dalam penelitiannya yang berjudul Effect of Job Satisfaction on Turnover Intention: An Empirical Investigation on Nigerian Banking Industry yang menemukan bahwa terdapat bahwa terdapat korelasi negatif dan signifikan antara kepuasan kerja terhadap turnover intention. Hal ini diperkuat oleh penelitian yang dilakukan oleh Leisanyane dan Khaola (2013) dalam penelitiannya yang berjudul the case of clay brick manufacturing company in lesotho yang menemukan bahwa terdapat korelasi negatif dan signifikan antara kepuasan kerja dan turnover intention.

Rageb et al. (2013) dalam penelitian bahwa kepuasan kerja berpengaruh negatif dan signifikan terhadap turnover intention. Youcef et al. (2016) dalam penelitiannya kepuasan kerja berpengaruh negatif pada turnover intention. Saeka (2016) mendapatkan hasil bahwa kepuasan kerja berpengaruh negatif terhadap turnover intention. Young dan Kwon menyatakan dalam penelitiannya kepuasan kerja berpengaruh negatif dan signifikan terhadap turnover intention. Ghandi et.al (2017) menyatakan bahwa kepuasan kerja berpengaruh langsung kepuasan kerja terhadap turnover intention. Begitu juga dengan penelitian yang dilakukan 
Susiani (2014) pada perusahaan The Stones Entertaiment Center yang berlokasi di Kuta, Bali menyatakan bahwa kepuasa kerja berpengaruh negatif pada turnover intention. Aspek kepuasan kerja seperti pembentukan suasana kekeluargaan serta kesempatan memperoleh kenaikan jabatan meningkatkan kepuasan kerja membuat karyawan untuk tetap bekerja pada perusahaan.

Hal ini berarti jika kepuasan kerja yang dirasakan oleh karyawan tinggi, maka berpengaruh pada rendahnya tingkat turnover intention karyawan pada PT. Bank Rakyat Indonesia (Persero )Tbk Cabang Gatot Subroto Denpasar. Rumusan hipotesis dapat dinyatakan sebagai berikut.

$\mathrm{H}_{3}$ : Kepuasan Kerja berpengaruh negatif terhadap Turnover Intention pada PT. Bank Rakyat Indonesia (Persero) Tbk. Cabang Gatot Subroto Denpasar.

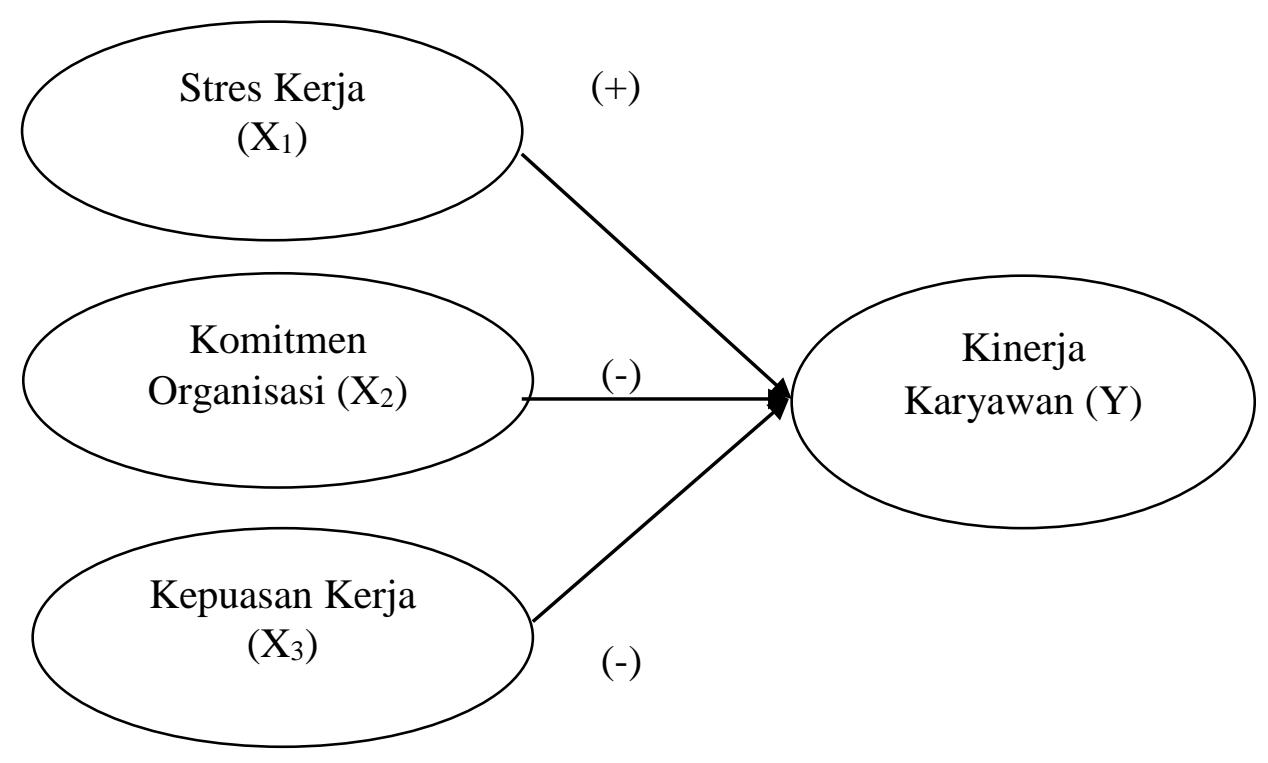

Gambar 1. Kerangka Konseptual 


\section{METODE PENELITIAN}

Penelitian ini ialah penelitian penelitian asosiatif (pengaruh) karena dalam penelitian ini memiliki tujuan untuk mengetahui pengaruh sebab akibat dari variabel-variabel yang diteliti (Sugiyono, 2013:5). Variabel yang diteliti dalam penelitian ini adalah Stres Kerja $\left(\mathrm{X}_{1}\right)$, Komitmen Organisasi $\left(\mathrm{X}_{2}\right)$, Kepuasan Kerja Karyawan $\left(\mathrm{X}_{3}\right)$ sebagai variabel bebas, serta Turnover Intention (Y) sebagai variabel terikat.

Lokasi penelitian dilakukan pada PT. Bank Rakyat Indonesia (Persero) Tbk. Cabang Gatot Subroto Denpasar yang berlokasi di Jalan Gatot Subroto No. 362 Denpasar, Bali. Adapun alasan melaksanakan penelitian di PT. Bank Rakyat Indonesia (Persero) Tbk. Cabang Gatot Subroto Denpasar dimana perusahaan ini mempunyai masalah terhadap turnover intention. Sedangkan objek penelitiannya adalah stres kerja, komitmen organisasi, kepuasan kerja dan turnover intention pada PT. Bank Rakyat Indonesia (Persero) Tbk. Cabang Gatot Subroto Denpasar. Variabel terikat dalam penelitian ini adalah Turnover intention (Y) yang diukur dengan menggunakan tiga indikator yaitu malas bekerja, peningkatan sanksi terhadap pelanggaran tata tertib kerja, dan peningkatan protes terhadap atasan. Variabel bebas dalam penelitian ini adalah stres kerja, komitmen organisasi, dan kepuasan kerja. Stres kerja (X1) diukur dengan menggunakan lima indikator yaitu beban kerja, desakan waktu, frustasi, konflik peran, dan konflik antar kelompok. Komitmen organisasi (X2) diukur dengan menggunakan tiga indikator yaitu komitmen afektif, komitmen berkelanjutan, dan komitmen normatif. Kepuasan kerja (X3) diukur dengan menggunakan lima indikator yaitu prestasi, pengakuan, pekerjaan itu sendiri, pertumbuhan, dan peluang untuk maju. 
Jenis data yang digunakan dalam penelitian ini adalah data kuantitatif berupa data jumlah absensi, jumlah karyawan dan hasil perhitungan statistik (SPSS). Data kualitatif berupa sejarah perusahaan, gambaran umum perusahaan, struktur organisasi, dan uraian jabatan karyawan. Sedangkan sumber data yang digunakan dalam penelitian ini adalah sumber primer berupa data yang didapatkan dengan observasi langsung dan kuesioner yang disebarkan kepada responden yaitu karyawan pada PT. Bank Rakyat Indonesia (Persero) Tbk. Cabang Gatot Subroto Denpasar. Sumber sekunder diperoleh dari perusahaan dalam bentuk sudah jadi, seperti sejarah perusahaan dan struktur organisasi perusahaan.

Populasi dalam penelitian ini adalah seluruh karyawan pada PT. Bank Rakyat Indonesia (Persero) Tbk. Cabang Gatot Subroto Denpasar yang berjumlah 70 karyawan bagian AO, AAO, FO, ADK Komersial, ADK Consumer, Teller, CS. Dalam penelitian ini tidak digunakan teknik sampling yang diteliti adalah keseluruhan dari populasi yang ada atau disebut sensus, mengingat jumlah populasi hanya sebesar 70 karyawan, maka layak untuk diambil keseluruhan untuk dijadikan responden tanpa harus mengambil sampel dalam jumlah tertentu.

Metode pengumpulan data yang digunakanadalam penelitianainiaadalah metode kuesioner, wawancara, dan observasi. Kuesioner dengan mempergunakan daftar pertanyaan yang disebarkan kepada responden yaitu karyawan pada PT. Bank Rakyat Indonesia (Persero) Tbk. Cabang Gatot Subroto Denpasar mengenai stres kerja, komitmen organisasi dan kepuasan terhadap turnover intention. Wawancara dengan melakukan wawancara secara langsung dengan karyawan pada PT. Bank Rakyat Indonesia (Persero) Tbk. Cabang Gatot Subroto Denpasar. Observasi dilakukan dengan cara mengamati situasi keadaan perusahaan secara 
langsung: aktivitas, kejadian, peristiwa, objek, kondisi atau suasana tertentu, dan perasaan emosi seseorang.

Penelitian ini menggukanan teknik analisis regresi linear berganda. Uji ini bertujuan untuk mencari pengaruh stres kerja $\left(\mathrm{X}_{1}\right)$, komitmen organisasi $\left(\mathrm{X}_{2}\right)$, kepuasan kerja $\left(\mathrm{X}_{3}\right)$ dan turnover intention $(\mathrm{Y})$. Teknik pengolahan data penelitian ini menggunakan program IBM SPSS Statistics version 20. Model regresi linear berganda yang digunakan adalah dengan menggunakan rumus:

$$
\mathrm{Y}=\mathrm{a}+\mathrm{b}_{1} \mathrm{X}_{1}+\mathrm{b}_{2} \mathrm{X}_{2}+\mathrm{b}_{3} \mathrm{X}_{3}+\mathrm{e}_{1}
$$

Keterangan :

$$
\begin{aligned}
& \mathrm{Y}=\text { turnover intention } \\
& \mathrm{a}=\text { konstanta } \\
& \mathrm{X}_{1}=\text { stres kerja } \\
& \mathrm{X}_{2}=\text { komitmen organisasi } \\
& \mathrm{X}_{3}=\text { kepuasan kerja } \\
& \mathrm{b}_{1}=\text { koefisien regresi stres kerja } \\
& \mathrm{b}_{2}=\text { koefisien regresi komitmen organisasi } \\
& \mathrm{b}_{3}=\text { koefisien regresi kepuasan kerja } \\
& \mathrm{e}_{1}=\text { koefisien pengganggu }
\end{aligned}
$$

\section{HASIL DAN PEMBAHASAN}

\section{Karakteristik Responden}

Berdasarkan data dari 70 responden PT. Bank Rakyat Indonesia (Persero) Tbk. Cabang Gatot Subroto Denpasar, karakteristik responden dilihat dari beberapa kriteria, yaitu umur, jenis kelamin, lama bekerja, dan jenis pendidikan. Karakteristik reponden diuraikan sebagai berikut.

Tabel 1 menunjukkan presentase responden perempuan sebesar 41,4 persen dan responden laki-laki sebesar 58,6 persen. Hal ini menunjukkan bahwa 
responden laki-laki lebih banyak dibandingkan responden perempuan. Berdasarkan usia menunjukkan kelompok umur yang paling dominan adalah pada usia 22-27 tahun dengan presentase 44,2 persen.

Tabel 1.

Karakteristik Responden

\begin{tabular}{|c|c|c|c|c|}
\hline No & Variabel & Klasifikasi & Jumlah & Persentase (\%) \\
\hline \multirow[t]{2}{*}{1} & \multirow[t]{2}{*}{ Jenis Kelamin } & Laki-laki & 41 & 58,6 \\
\hline & & Perempuan & 29 & 41,4 \\
\hline \multicolumn{3}{|c|}{ Jumlah } & 70 & 100 \\
\hline \multirow[t]{4}{*}{2} & \multirow[t]{4}{*}{ Usia } & 22-27 Tahun & 31 & 44,2 \\
\hline & & 28-33 Tahun & 15 & 21,4 \\
\hline & & 34-39 Tahun & 13 & 18,6 \\
\hline & & $\geq 40$ Tahun & 11 & 15,8 \\
\hline \multicolumn{3}{|c|}{ Jumlah } & 70 & 100 \\
\hline \multirow[t]{6}{*}{3} & \multirow[t]{5}{*}{ Lama Bekerja } & 1-7 Tahun & 9 & 12,9 \\
\hline & & 8-14 Tahun & 27 & 38,5 \\
\hline & & 15-21Tahun & 13 & 18,6 \\
\hline & & 22-28Tahun & 11 & 15,8 \\
\hline & & $\geq 29$ Tahun & 10 & 14,2 \\
\hline & Jumlah & & 70 & 100 \\
\hline \multirow[t]{4}{*}{4} & \multirow[t]{3}{*}{ Jenis Pendidikan } & D3 & 18 & 25,7 \\
\hline & & S1 & 30 & 42,9 \\
\hline & & $\mathrm{S} 2$ & 22 & 31,4 \\
\hline & Jumlah & & 70 & 100 \\
\hline
\end{tabular}

Sumber: Data primer, data diolah, 2017

Sedangkan untuk kelompok umur yang terendah adalah pada usia $\geq 40$ tahun dengan presentase 15,8 persen. Berdasarkan lama bekerja menunjukkan pengelompokan responden berdasarkan lamanya bekerja paling dominan adalah 8-14 tahun dengan presentase 38,5 persen. Sedangkan untuk kelompok lama bekerja yang terendah 1-7 tahun dengan presentase 12,9 persen. Berdasarkan pendidikan terakhir menunjukkan responden tertinggi memiliki jenis pendidikan S1 dengan presentase 42,9 persen. Sedangkan jumlah terendah adalah responden yang memiliki jenis pendidikan D3 dengan presentase 25,7 persen. 


\section{Hasil Uji Validitas}

Suatu kuisioner dikatakan valid jika butir pertanyaan mampu mengungkapkan sesuatu yang diukur oleh kuisioner tersebut. Uji Validitas dilakukan dengan mengkorelasikan antara skor faktor dengan skor total dan bila korelasi tiap faktor tersebut positif $>0,30$ maka dinyatakan valid.

Tabel 2.

Hasil Uji Validitas Instrumen

\begin{tabular}{ccccc}
\hline No. & Variabel & Indikator & Koefisien Korelasi & Keterangan \\
\hline & & $\mathrm{X} 1.1$ & 0,885 & Valid \\
1. & Stres Kerja & $\mathrm{X} 1.2$ & 0,841 & Valid \\
& $(\mathrm{X} 1)$ & $\mathrm{X} 1.4$ & 0,843 & Valid \\
& & $\mathrm{X} 1.5$ & 0,863 & Valid \\
& Komitmen & $\mathrm{X} 2.1$ & 0,823 & Valid \\
\hline \multirow{3}{*}{ 2. } & Organisasi & $\mathrm{X} 2.2$ & 0,888 & Valid \\
& $(\mathrm{X} 2)$ & $\mathrm{X} 2.3$ & 0,897 & Valid \\
& \multirow{2}{*}{ Kepuasan Kerja } & $\mathrm{X} 3.1$ & 0,871 & Valid \\
\hline \multirow{3}{*}{ 3. } & $(\mathrm{X} 3)$ & $\mathrm{X} 3.2$ & 0,877 & Valid \\
& & $\mathrm{X} 3.3$ & 0,821 & Valid \\
& & $\mathrm{X} 3.4$ & 0,856 & Valid \\
& \multirow{2}{*}{ 4urnover } & $\mathrm{Y} 1.1$ & 0,832 & Valid \\
\hline \multirow{2}{*}{ Intention } & $\mathrm{Y} 1.2$ & 0,790 & Valid \\
& & $\mathrm{Y} 1.3$ & 0,809 & Valid \\
& & & & Valid \\
\hline
\end{tabular}

Sumber: Data primer, data diolah, 2017

Tabel 2. diatas menunjukkan bahwa hasil uji validitas dari masingmasing indikator yang digunakan menghasilkan koefisien korelasi dengan validitas tertinggi 0,921 dan koefisien korelasi dengan validitas terendah yaitu 0,790. Maka hasil uji validitas menunjukkan bahwa seluruh koefisien korelasi dari 15 indikator dengan 70 responden memiliki nilai lebih dari 0,30 , dapat disimpulkan bahwa seluruh indikator dalam penelitian ini dinyatakan valid atau memenuhi syarat validitas data. 
Uji reliabilitas dilakukan untuk mengukur konsistensi jawaban atas pertanyaan yang diberikan didalam kuisioner yang digunakan sebagai alat ukur dalam penelitian ini. Hasil dari uji statistic Cronbach Alpha apabila lebih besar dari 0,60 menunjukkan bahwa instrument yang digunakan reliabel.

Tabel 3.

Hasil Uji Reabilitas

\begin{tabular}{ccc}
\hline Variabel & Cronbach Alpha & Keterangan \\
\hline X1 & 0,904 & Reliabel \\
X2 & 0,844 & Reliabel \\
X3 & 0,901 & Reliabel \\
Y & 0,738 & Reliabel \\
\hline
\end{tabular}

Sumber: Data primer, data diolah, 2017

Hasil uji reliabilitas yang disajikan dalam Tabel 3. menunjukkan bahwa keempat instrument penelitian memiliki koefisien Cronbach Alpha lebih dari 0,60. Hal ini dapat dikatakan bahwa semua instrument reliable sehingga dapat digunakan untuk melakukan penelitian.

\section{Hasil Analisis Faktor Konfirmatori}

Uji Kaiser Meyer Olkin (KMO) digunakan untuk mengetahui kecukupan sampel. Analisis faktor dianggap layak jika besaran KMO memiliki nilai minimal 0,5. Hasil uji KMO dapat dilihat pada Tabel 4.

\section{Tabel 4}

Conformatory Factor Analysis (CFA)

\begin{tabular}{ccrccl}
\hline Var & KMO & Sig. & Communalities & Component Matrix & Comulative \% \\
\hline X1 & 0,794 & 0,000 & 0,624 & 0,790 & 67,347 \\
X2 & 0,718 & 0,000 & 0,820 & 0,905 & 77,928 \\
X3 & 0,813 & 0,000 & 0,783 & 0,855 & 77,300 \\
Y & 0,670 & 0,000 & 0,658 & 0,811 & 66,028 \\
\hline
\end{tabular}

Sumber: Data primer, data diolah, 2017 
Tabel 4. menunjukkan bahwa nilai Kaiser Meyer Olkin (KMO) untuk masing-masing variabel lebih besar dari 0,5 dengan signifikansi lebih kecil $\alpha=0,05$. Jadi, dapat disimpulkan bahwa masing-masing variabel mempunyai kecukupan sampel untuk melakukan analisis faktor.

\section{Hasil Uji Normalitas}

Uji normalitas bertujuan untuk menguji apakah suatu data berdistribusi normal atau tidak. Penentuan normal atau tidaknya distribusi data dapat dilakukan penghujian dengan menggunakan Kolomogorov Smirnov.

Tabel 5.

Hasil Uji Normalitas

\begin{tabular}{|c|c|c|c|c|}
\hline & & \multicolumn{3}{|c|}{ Unstandardized Residual } \\
\hline \multicolumn{2}{|l|}{$\overline{\mathrm{N}}$} & & & 70 \\
\hline \multirow[t]{2}{*}{ Normal Parameters a,b } & Mean & & & .0000000 \\
\hline & Std. Deviation & & & .49937565 \\
\hline \multirow{3}{*}{$\begin{array}{l}\text { Most Extreme } \\
\text { Differences }\end{array}$} & Absolute & & .065 & \\
\hline & Positive & & .065 & \\
\hline & Negative & -.054 & & \\
\hline \multicolumn{2}{|l|}{ Kolmogorov-Smirnov } & & .547 & \\
\hline \multicolumn{2}{|l|}{ Z Asymp. Sig. (2- } & & .926 & \\
\hline
\end{tabular}

Sumber: Data primer, data diolah, 2017

Tabel 5. menunjukkan bahwa nilai Asymp. Sig (2-tailed) sebesar 0,926. Oleh karena nilai Asymp. Sig. (p-value) 0,926 lebih besar daripada $\alpha(0,05)$ maka, dapat diinterpretasikan bahwa residual model telah berdistribusi normal.

\section{Hasil Uji Heteroskedasitas}

Uji heteroskedastisitas dilakukan untuk mengetahui bahwa model regresi terjadi ketidaksamaan varian dari residual satu ke pengamatan yang lain tetap maka disebut heteroskedastisitas (Ghozali, 2009). Untuk mendeteksi ada atau 
tidaknya heteroskedastisitas dapat dilakukan dengan Uji Glejser, yaitu dengan meregres variabel terhadap absolut residual. Jika variabel terikat signifikan mempengaruhi variabel bebas, maka ada indikasi terjadi heteroskedastisitas.

\begin{tabular}{|c|c|c|c|c|c|c|}
\hline \multicolumn{7}{|c|}{$\begin{array}{c}\text { Tabel } 6 . \\
\text { Hasil Uji Heteroskedastisitas }\end{array}$} \\
\hline & & \multicolumn{2}{|c|}{$\begin{array}{l}\text { Unstandardized } \\
\text { Coefficient }\end{array}$} & \multirow{2}{*}{$\begin{array}{c}\text { Standardized } \\
\text { Coefficients } \\
\text { Beta }\end{array}$} & & \\
\hline & & B & Std. Error & & & \\
\hline 1 & (Constant) & .385 & .038 & & 10.204 & .000 \\
\hline & Stres kerja & -.059 & .048 & -.188 & -1.241 & .219 \\
\hline & Komitmen org. & -.020 & .052 & -.065 & -.389 & .699 \\
\hline & Kepuasan kerja & .021 & .045 & .065 & .457 & .649 \\
\hline
\end{tabular}

Sumber: Data primer, data diolah, 2017

Berdasarkan olahan data dengan SPSS pada Tabel 6. dilihat bahwa tidak ada pengaruh variabel bebas $\left(\mathrm{X}_{1}, \mathrm{X}_{2}\right.$, dan $\left.\mathrm{X}_{3}\right)$ terhadap absolut residual (abs- res), baik secara serempak maupun parsial karena Sig. lebih besar 0,05. Dengan demikian model yang dibuat tidak mengandung gejala heteroskedastisitas, sehingga layak untuk memprediksi variabel dependen.

\section{Hasil Analisis Regresi Linear Berganda}

Model analisis linier berganda digunakan untuk mencari koefisien regresi yang akan menentukan apakah hipotesis yang akan dibuat diterima atau ditolak. Hasil analisis yang disajikan pada Tabel 7. dapat disusun persamaan regresi sebagai berikut.

$$
\hat{\mathrm{Y}}=0,000+0,593 \mathrm{X}_{1}-0,179 \mathrm{X}_{2}-0,269 \mathrm{X}_{3}
$$

Keterangan:

$\mathrm{Y} \quad=$ Turnover Intention

$\mathrm{X}_{1} \quad=$ Stres Kerja

$\mathrm{X}_{2} \quad=$ Komitmen Organisasi

$\mathrm{X}_{3}=$ Kepuasan Kerja 
Tabel 7.

Hasil Analisis Regresi Linier Berganda

\begin{tabular}{lccccr}
\hline \multicolumn{7}{c}{$\begin{array}{c}\text { Unstandardized } \\
\text { Coefficients }\end{array}$} & $\begin{array}{c}\text { Standardized } \\
\text { Coefficients } \\
\text { Koefisien }\end{array}$ & B & Std. Eror & Beta & T & Sig. \\
\hline Konstanta (a) & 0,000 & 0,061 & & 0,000 & 1,000 \\
$\quad$ Stres Kerja & 0,593 & 0,077 & 0,593 & 7,716 & 0,000 \\
$\quad$ Komitmen & & & & & \\
$\quad$ Organisasi & $-0,179$ & 0,084 & $-0,179$ & $-2,124$ & 0,037 \\
Kepuasan Kerja & $-0,269$ & 0,073 & $-0,269$ & $-3,704$ & 0,000 \\
\hline F hitung & & $: 66.220$ & & & \\
Signisikansi F & $: 0,000$ & & & \\
R Square & $: 0,751$ & & & \\
Adjusted R Square & $: 0,739$ & & & \\
Sumber: Data primer, data diolah, 2017 &
\end{tabular}

Nilai $\mathrm{X}_{1}=0,593$, berarti bahwa stres kerja memiliki pengaruh positif terhadap turnover intention karyawan pada Pada PT. Bank Rakyat Indonesia (Persero) Tbk. Cabang Gatot Subroto Denpasar. Hal ini menunjukkan bahwa setiap peningkatan 1 persen stres kerja, maka turnover intention mengalami peningkatan sebesar 0,593 persen dengan asumsi variabel lain konstan, dan sebaliknya. Nilai $\mathrm{X}_{2}=-0,179$, berarti bahwa komitmen organisasi memiliki pengaruh negatif terhadap turnover intention karyawan pada Pada PT. Bank Rakyat Indonesia (Persero) Tbk. Cabang Gatot Subroto Denpasar. Nilai $\mathrm{X}_{3}=-$ 0,269, berarti bahwa kepuasan kerja memiliki pengaruh negatif terhadap turnover intention karyawan pada Pada PT. Bank Rakyat Indonesia (Persero) Tbk. Cabang Gatot Subroto Denpasar. Hal ini menunjukkan bahwa setiap peningkatan 1 persen kepuasan kerja, maka turnover intention mengalami penurunan 0,269 persen dengan asumsi variabel lain konstan, dan sebaliknya.

Nilai $\mathrm{R}^{2}=0,751$, berarti bahwa stres kerja, komitmen organisasi dan kepuasan kerja terhadap turnover intention pada Pada PT. Bank Rakyat Indonesia 
(Persero) Tbk. Cabang Gatot Subroto Denpasar sebesar 75,1 persen, sedangkan sisanya sebesar 24,9 persen dipengaruhi oleh faktor lainnya yang tidak dijelaskan dalam model.

\section{Hasil Uji Kelayakan Model (Uji F)}

Hasil uji $\mathrm{F}$ dapat dijelaskan dengan nilai signifikan anova $<\alpha=0,05$ maka model ini dikatakan layak atau variabel bebas mampu dijelaskan variabel terikat, uji F dapat dilihat dalam Tabel 8.

\section{Tabel 8.}

Hasil Uji F

\begin{tabular}{llccccc}
\hline & Model & Sum of Squares & df & Mean Square & F & Sig. \\
\hline 1 & Regression & 51.793 & 3 & 17.264 & 66.220 & $.000^{\mathrm{a}}$ \\
& Residual & 17.207 & 66 & .261 & & \\
& Total & 69.000 & 69 & & & \\
\hline
\end{tabular}

Sumber: Data primer, data diolah, 2017

Tabel 8. menunjukkan nilai signifikan sebesar 0,000 yang lebih kecil dari $\alpha=0,05$ maka model regresi linier berganda layak digunakan sebagai alat analisis untuk menguji pengaruh variabel bebas terhadap terikat.

\section{Hasil Uji t}

Tabel 7. nilai signifikan uji t sebesar 0,000. Hasil analisis pengaruh stres kerja terhadap Turnover Intention diperoleh Sig. t sebesar 0,000 dengan koefisien beta $(\beta) 0,593$. Nilai sig. t $0,000<0,05$ mengindikasikan bahwa $\mathrm{H}_{0}$ ditolak dan $\mathrm{H}_{1}$ diterima. Hasil ini mempunyai arti bahwa Stres Kerja berpengaruh positif terhadap Turnover Intention.

Tabel 7. nilai signifikan uji t sebesar 0,037. Hasil analisis pengaruh stres kerja terhadap Turnover Intention diperoleh Sig. t sebesar 0,037 dengan koefisien beta $(\beta)-0,179$. Nilai sig. t $0,037<0,05$ mengindikasikan bahwa $\mathrm{H}_{0}$ ditolak dan 
$\mathrm{H}_{1}$ diterima. Hasil ini mempunyai arti bahwa Komitmen Organisasi berpengaruh negatif terhadap Turnover Intention.

Tabel 7. nilai signifikan uji t sebesar 0,000. Hasil analisis pengaruh stres kerja terhadap Turnover Intention diperoleh Sig. t sebesar 0,000 dengan koefisien beta $(\beta)-0,269$. Nilai sig. t $0,000<0,05$ mengindikasikan bahwa $\mathrm{H}_{0}$ ditolak dan $\mathrm{H}_{1}$ diterima. Hasil ini mempunyai arti bahwa Kepuasan Kerja berpengaruh negatif terhadap Turnover Intention.

\section{Pengaruh Stres Kerja Terhadap Turnover Intention Pada PT. Bank Rakyat Indonesia (Persero) Tbk. Cabang Gatot Subroto Denpasar}

Pengujian untuk hipotesis pertama menunjukkan bahwa stres kerja berpengaruh positif dan signifikan terhadap turnover intention pada PT. Bank Rakyat Indonesia (Persero) Tbk. Cabang Gatot Subroto Denpasar. Tingkat stres karyawan pada PT. Bank Rakyat Indonesia (Persero) Tbk. Cabang Gatot Subroto Denpasar sebagian besar disebabkan oleh adanya ketidaknyamanan konflik kerja antar kelompok. Dalam hal ini konflik kerja harus bisa diperkecil dengan mengaadakan pertemuan rutin di dalam organisasi perusahaan itu sendiri dan meningkatkan kualitas supervise yang lebih baik untuk merendam ketidaknyamanan konflik kerja yang telah terjadi di perusahaan itu sendiri. Sebaiknya tingginya tingkat stres kerja pada karyawan dapat di turunkan untuk meminimalisir tingginya tingkat turnover intention pada PT. Bank Rakyat Indonesia (Persero) Tbk. Cabang Gatot Subroto Denpasar.

Disimpulkan bila stres kerja menurun maka tingginya tingkat turnover intention pada karyawan PT. Bank Rakyat Indonesia (Persero) Tbk. Cabang Gatot 
Subroto Denpasar juga akan menurun. Ini menunjukkan bahwa variabel independent stres kerja $\left(\mathrm{X}_{1}\right)$ terbukti berpengaruh positif signifikan terhadap variabel dependent turnover intention (Y) intention pada karyawan PT. Bank Rakyat Indonesia (Persero) Tbk. Cabang Gatot Subroto Denpasar. Hasil penelitian ini mengembangkan penelitian yang dilakukan oleh Anggraini (2013), Waspodo dkk., (2013), Arnanta, dkk., (2017), Mitchell et al. (2014), Arshadi et al. (2013), Byoung, dkk (2016)

\section{Pengaruh Komitmen Organisasi Terhadap Turnover Intention Pada PT. Bank Rakyat Indonesia (Persero) Tbk. Cabang Gatot Subroto Denpasar}

Pengujian untuk hipotesis kedua menunjukkan bahwa komitmen organisasi berpengaruh negatif dan signifikan terhadap turnover intention pada PT. Bank Rakyat Indonesia (Persero) Tbk. Cabang Gatot Subroto Denpasar. Tingkat komitmen organisasi karyawan pada PT. Bank Rakyat Indonesia (Persero) Tbk. Cabang Gatot Subroto Denpasar sebagian besar disebabkan oleh adanya perasaan bangga menjadi bagian dari organisasi. Hal ini dapat mencapai tujuan aktivitas organisasi dengan cara pimpinan memberikan semangat, motivasi dan arahan yang lebih baik lagi, serta mengutamakan komunikasi yang baik antar rekan kerja di perusahaan.

Disimpulkan bila mempunyai perasaan bangga menjadi bagian dari organisasi meningkat, maka tingkat turnover intention pada karyawan PT. Bank Rakyat Indonesia (Persero) Tbk. Cabang Gatot Subroto Denpasar juga akan menurun. Ini menunjukkan bahwa variabel independent komitmen organisasi $\left(\mathrm{X}_{2}\right)$ terbukti berpengaruh negatif signifikan terhadap variabel dependent turnover intention (Y) intention pada karyawan PT. Bank Rakyat Indonesia (Persero) Tbk. 
Cabang Gatot Subroto Denpasar. Hasil penelitian ini mengembangkan penelitian yang dilakukan oleh Menurut Jehanzeb,dkk. (2013), Jonathan, et al. (2013), Monica (2017), Kumar et al (2013), Sianipar dan Haryanti (2014), Anneswary dan Arsiah (2015).

\section{Pengaruh Kepuasan Kerja Terhadap Turnover Intention Pada PT. Bank Rakyat Indonesia (Persero) Tbk. Cabang Gatot Subroto Denpasar}

Pengujian untuk hipotesis ketiga menunjukkan bahwa kepuasan kerja berpengaruh negatif dan signifikan terhadap turnover intention pada PT. Bank Rakyat Indonesia (Persero) Tbk. Cabang Gatot Subroto Denpasar. Tingkat kepuasan kerja karyawan pada PT. Bank Rakyat Indonesia (Persero) Tbk. Cabang Gatot Subroto Denpasar sebagian besar disebabkan oleh adanya pekerjaan yang menyenangkan di dalam perusahaan. Hal ini dapat membuat turnover intention menurun apabila karyawan merasa puas berada di perusahaan. Karyawan merasa puas memiliki pekerjaan yang menyenangkan tentu akan merasa nyaman untuk berada di perusahaannya, dan karyawan yang merasa tidak puas akan keluar dari perusahaan. Karyawan pada PT. Bank Rakyat Indonesia (Persero) Tbk. Cabang Gatot Subroto Denpasar merasa puas dengan pekerjaannya maka pimpinan hendaknya memberikan kesempatann kerja yang lebih baik dengan cara memberikan kesempatan peningkatan pengalaman dan kemampuan karyawan selama bekerja. Hasil penelitian ini mengembangkan penelitian yang dilakukan oleh Leisanyane dan Khaola (2013), Susiani (2014), Saeka (2016), Ibrahim et.al (2016), Ghandi et.al.(2017). 


\section{SIMPULAN DAN SARAN}

Berdasarkan pembahasan hasil penelitian di atas, dapat disimpulkan bahwa stres kerja berpengaruh positif dan signifikan terhadap turnover intention karyawan pada PT. Bank Rakyat Indonesia (Persero) Tbk. Cabang Gatot Subroto Denpasar. Sedangkan komitmen organisasi dan kepuasan kerja berpengaruh negatif dan signifikan terhadap turnover intention karyawan pada PT. Bank Rakyat Indonesia (Persero) Tbk. Cabang Gatot Subroto Denpasar. Sementara itu, saran yang dapat diberikan untuk meminimalisir tingkat stres kerja karyawan maka hendaknya perusahaan memberikan pekerjaan yang sesuai dengan bidangnya, dan tingkat beban kerja karyawan yang sesuai dengan kemampuan karyawan. Perusahaan diharapkan meningkatkan komitmen karyawan dengan memberikan dukungan dan perhatian kepada karyawannya, dan memberikan kepuasan karyawan yang dapat memacu semangat kerja karyawan. Penelitian selanjutnya diharapkan menambah variabel dan mengambil sampel diluar lingkungan perbankan serta menggunakan model lain sebagai alat analisisnya.

\section{REFERENSI}

Agung, W., N. C. Handayani., dan W. Paramita. 2013. Pengaruh Kepuasan Kerja dan Stres Kerja Terhadap Turnover Intention Karyawan PT. Unitex Bogor. Jurnal Riset Manajemen Sains Indonesia (JRMSI), 4(1), 97-115.

Ahmad, B., M. Shahid., H. Zill., and H. Sajjad. 2012. Turnover Intention: An HRM Issue In Textile Sector. Interdisciplinary Journal Of Contemporary Research In Business, 3(12), 125-130. 
Anggraini, M. I. 2013. Pengaruh Kepuasan Kerja, Komitmen Organisasional dan Stres Kerja Terhadap Keinginan Untuk Keluar. Universitas Atmajaya. Tesis. Yogyakarta.

Anis, K. 2003. Pengaruh Kepuasan Kerja dan Komitmen Organisasional Terhadap Keinginan Berpindah Kerja Auditor (Studi Kasus pada KAP di Jawa Tengah). Jurnal Ekonomi dan Bisnis, 4(2), 141-152.

Arnanta, I. G. P., dan I. W. Mudiartha. 2017. Pengaruh Stres Kerja, Kepuasan Kerja dan Iklim Kerja Terhadap Turnover Intention KaryawanCV. DHARMA SIADJA. E-Jurnal Manajemen Universitas Udayana, 6(6).

Arshadi, N., dan D. Hojaat. 2013. The Relationship of Job Stress with Turnover Intention and Job Perfomance: Moderating Role of OBSE. Procedia Social and Behavioralv Sciences. 84(1), 706-710.

Fah, C. B., S. Y. Foon., C. Leong., dan S. Osman. 2010. An Exploratory Study on Turnover Intention among Private Sector Employees. International Journal of Business and Management, 5(8), 57-64.

Ghandi, P., E. Hejazi., dan N. Ghandi. 2017. A Study on the Relationship between Resilience and Turnover Intention: With an Emphasis on the Mediating Roles of Job. Bulletin de la Société Royale des Sciences de Liège. 86, 189200.

Hanafiah, M. 2014. Pengaruh Kepuasan Kerja dan Ketidakamanan kerja (Job Insecurity) dengan intensi Pindah Kerja (Turnover) Pada Karyawan PT. Buma Desa Suaran Kecamatan Sambaliung Kabupaten Berau. E-Jurnal Psikologi, 1(3), 303-312.

Haq, M. A., U. Y. Jindong., dan H. Zafar. 2014. Factor Affecting Organizational Commitment Among Bank In Pakistan. Journal Business and Management, 16(4), 18-24.

Ibrahim, M. G., H. Hilman., dan N. Kaliappen. 2016. "Effect of Job Satisfaction on Turnover Intention: An Empirical Investigation on Nigerian Bank Industry. International Journal of Organizational and Business Excellence, $1(2)$.

Jehanzeb, K., A. Rasheed dan F. Rasheed. 2013. Organizational Commitment and Turnover Intentions: Impact of Employee's Training in Private Sector of Saudi Arabia. International Journal of Business and Management, 8(8), 7990.

Joarder, M., S. Mohamad and A. Kawsar 2011. Mediating Role Of Affective Commitment in HRM Praktices and Turnover Intention Relationship : A 
Study in Developing Context. Business and Economics Research Journal, 2(4), 135-158.

Jonathan, H., T. Motena and C. Darroux. 2013. impact Investigation of Organizational Commitment on Intention to Leave of Public Secondary School Teachers in Tanzania. Developing Country Studies, 3(11).

Kalidass, A. dan A. Bahron. 2015. The Relationship between Perceived Supervisor Support, Perceived Organizational Support, Organizational Commitmen and Employee Turnover Intention. International Journal of Business Administration, 6(5).

Leisanyane, K., dan P. P. Khaola. 2013. The Influence Of Organisational Culture and Job Satisfaction on Intentions To Leave: The Case Of Clay Brick Manufacturing Company In Lesotho. EASSRR. 29(01), 59-75.

Lu, Chia-Ju, Yi-Yu Shih, and Yi-Lien Chen. 2013. Effects of Emotional Labor and Job Satisfaction on Organizational Citizenship Behaviors: A Case Study On Business Hotel Chains. The International Journal of Organizational Innovation, 5(4), 165-176.

Mahdi, A., M. Zaid., M. Roslan., A. Asmidi and A. Sulaiman. 2012. The Relationship Between Job Satisfaction And Turnover Intention. American Journal of Applied Scienes, 9(9), 1518-1526.

Manurung, T. M., dan I. Ratnawati. 2012. Analisis Pengaruh Stres Kerja dan Kepuasan Kerja Terhadap Turnover Intention Karyawan (Studi Pada Stikes Widya Husada Semarang). Diponegoro Journal Of Management, 1(2), 145157.

Mitchell, O. M., D. Layton., S. Gaylene., dan J. Gover. 2014. The Impact of Individual, Organizational, and Environmental Attributes on Voluntary Turnover Among Juvenile Correctional Staf Members. Justice Quarterly: Academy of Criminal Justice Science, 17(2), 332-357.

Monica, T. J., dan M. S. Putra. 2017. Pengaruh Stres Kerja, Komitmen Organisasi, dan Kepuasan Kerja Terhadap Turnover Intention. E-Jurnal Manajemen Universitas Udayana, 6(3).

Mosadeghrad, A. M. 2013. Occupational Stress and Turnover Intention: Implications for Nursing Management. International Journal of Health Policy dan Management, 1(2), 169-176.

Rageb, A. M., E. Mohamed., and S. Farid. 2013. Organizational Commitmen, Job Satisfaction and Job Perfomance as a Mediator between Role Stressors and Turnover Intention A Study from an Egyptian Cultural Perspective, 3(2). 
Robbins, S. P. Perilaku Organisasi: Konsep, kontroversi, aplikasi, Jakarta: Prenhallindo.

Robbins, P. S. 2006. Teori Organisasi Struktur, Desain \& Aplikasi. Edisi 3. Penerbit Arcan: Jakarta.

Robbins, P. S. 2010. Manajemen. Edisi Kesepuluh. Jakarta: Erlangga.

Saeka, I. P. P., dan I. W. Suana. 2016. Pengaruh Kepuasan Kerja, Komitmen Organisasional dan Stres Kerja Terhadap Turnover Intention karyawan PT. INDONUSA ALGA EMAS PRIMA BALI. E-Jurnal Manajemen Universitas Udayana, 5(6).

Septiadi, I. M. dan W. G. Supartha. 2013. Pengaruh Kepemimpinan, Komunikasi, dan Lingkungan Kerja Fisik Terhadap Kepuasan Kerja Pada PT. BPR Sriartha Lestari Denpasar. E-Journal Universitas Udayana, 2(8), 986-1001.

Siddiqui, A. A., and A. Jamil. 2015 Antecedes of Employees' Intentions: Evidence from Private Educational Institutions. American Journal of Economics and Business Administrasion, 7(4), 160-165

Sidharta, N. M. 2011. Dampak Komitmen Organisasi dan Kepuasan Kerja terhadap Turnover Intention : Studi Empiris pada Karyawan bagian Operator di salah satu Perusahaan Garmen di Cimahi. Jurnal Manajemen, 10(22), 129-142.

Suciati, A. T. H., dan M. M. Minarsih. 2015. Pengaruh Job Insecurity dan Stres kerja Terhadap Turnover Intention Pegawai pada karyawan PT. Berkat Abadi Surya Cermelang Semarang (HO). Jurnal, 1(1), 1-12.

Sugiyono. 2014. Metode penelitian Manajemen. Bandung: Alfabeta.

Sunyoto, D. 2015. "Penelitian Sumber Daya Manusia. Jakarta”, Jakarta: PT Buku Seru.

Susiani, V. 2014. Pengaruh Kepuasan Kerja dan Komitmen Organisasi pada Turnover Intention. Jurnal Manajemen. Fakultas Ekonomi dan Bisnis.

Sutanto E. M. dan C. Gunawan. 2013. Kepuasan Kerja, Komitmen Organisasional dan Turnover Intentions, Jurnal Mitra Ekonomi dan Manajemen Bisnis, $4(1)$.

Suwatno, J. P. 2013. Manajemen SDM dalam Organisasi Publik dan Bisnis. (Cetakan ketiga). Bandung: Alfabeta.

Sylvia, L. I., B. Swasto., dan G. Eko Nurtjahjono. 2014. Pengaruh Motivasi Kerja dan Disiplin Kerja terhadap Prestasi Kerja Karyawan (Studi Pada Karyawan 
PT. AXA Financial Indonesia Sales Office Malang). Jurnal Administratif Bisnis (JAB), 7(1), 1-8.

Tobing. 2009. Pengaruh Komitmen Organisasional dan Kepuasan Kerja Terhadap Kinerja Karyawan PT. Perkebunan Nusantara III di Sumatera Utara. Jurnal Manajemen Dan Kewirausahaan, 11(1), 31-37.

Velnampy, T. and S. A. Aravinthan. 2013. Occupational Stress and Organizational Commitment in Private Banks: A Sri Lanka Experience. European Journal of Business and Management, 5(7), 78-99.

Widodo, R. 2010. Analisis Pengaruh Keamanan Kerja dan Komitmen Organisasional terhadap Turnover Intention serta Dampaknya pada Kinerja karyawan Outsourcing (Studi pada PT. PLN Persero APJ Jakarta). Tesis. Semarang: Program Pasca Sarjana Magister Manajemen Universitas Diponogoro.

Youcef, S., S. S. Ahmed, B. Ahmed. 2016. The Impact of Job Satisfaction by the Existence of Organizational Commitment, and of Organizational Commitment, and Inten to Stay as Intermediates Variables Using approach PLS In Sample Worker Department of Transport Saida, 6(6), 198-202.

Young, K. K., dan H. J. Kwon. 2016. The Influence of Job Stress and Job Satisfaction on Turnover Intention for Male Dental Hygienists. Journal of Dental Hygiene Science, 16(2), 142-149. 